\title{
NEW MATHEMATICAL OPTIMIZATION MODELS FOR RFQ STRUCTURES ${ }^{*}$
}

\author{
B. I. Bondarev, A. P. Durkin, Moscow Radiotechnical Institute \\ A. D. Ovsyannikov ${ }^{\#}$, St.Petersburg State University
}

\section{Abstract}

Conventional approach to the designing of controlled systems is to start with calculation of program motion and to continue afterwards by examining perturbed motions using equations in deviations. It does not always, however, result in desirable outcomes. Thus, while analysing perturbed motions, which depend significantly on the program motion, it can happen, that dynamical characteristics of obtained perturbed motions are not satisfactory.

This paper suggests new mathematical models, which allow joint optimization of program motion and an ensemble of perturbed motions. These mathematical models include description of controlled dynamical process, choice of control functions or parameters of optimization as well as construction of quality functionals, which allow efficient evaluation of various characteristics of examined control motions.

This optimization problem is considered as the problem of mathematical control theory. The suggested approach allows to develop various methods of directed search and to conduct parallel optimization of program and perturbed motions. Suggested approach is applied to the optimization of RFQ channel. Simple model for description of beam longitudinal motion in the equivalent running wave is suggested. For the estimation of beam dynamics corresponding functionals are suggested.

\section{MATHEMATICAL MODELS OF OPTIMIZATION}

First we consider following dynamic system:

$$
\begin{aligned}
\frac{\mathrm{dx}}{\mathrm{dt}} & =\mathrm{f}(\mathrm{t}, \mathrm{x}, \mathrm{u}), \\
\frac{\mathrm{dy}}{\mathrm{dt}} & =\mathrm{F}(\mathrm{t}, \mathrm{x}, \mathrm{y}, \mathrm{u}),
\end{aligned}
$$

with initial conditions:

$$
\mathrm{x}(0)=\mathrm{x}_{0}, \quad \mathrm{y}(0)=\mathrm{y}_{0} \in \mathrm{M}_{0} \text {; }
$$

Here $\mathrm{t}$ is time, $\mathrm{x}$ is $\mathrm{n}$-vector, $\mathrm{u}=\mathrm{u}(\mathrm{t})$ is $\mathrm{r}$ dimensional control vector function, $\mathrm{y}-\mathrm{m}$-vector, $\mathrm{f}(\mathrm{t}, \mathrm{x}, \mathrm{u})$ and $\mathrm{F}(\mathrm{t}, \mathrm{x}, \mathrm{y}, \mathrm{u})$ are $\mathrm{n}$-dimensional and $\mathrm{m}$ dimensional

*Work supported in part by Russian Foundation for Fundamental Researches, project 99-01-00678

\# Email: ovs@apcp.apmath.spbu.ru vector functions correspondingly. We assume that $\mathrm{f}, \mathrm{F}$ and $\operatorname{div}_{\mathrm{y}} \mathrm{F}=\sum_{\mathrm{i}=1}^{\mathrm{m}} \partial \mathrm{F}_{\mathrm{i}} / \partial \mathrm{y}_{\mathrm{i}}$ are continuous with their partial derivatives. The set $\mathrm{M}_{0}$ is a given compact set in the phase space of nonzero measure in $\mathrm{R}^{\mathrm{m}}$. We assume that admissible controls $\mathrm{u}(\mathrm{t})$ constitute certain class $\mathrm{D}$ of functions, that are piecewise continuous on interval $[0, T]$ and have values in a compact set $\mathrm{U} \subset \mathrm{R}^{\mathrm{r}}$.

Equation (1) describes dynamics of synchronous particle. Here in this paper we will consider this motion as the program one. Equation (2) is the derivations equation describing perturbed motions.

Along with equations (1), (2) we consider changes of density of particles $\rho(t, y)$, along the system (2) trajectory:

$$
\begin{gathered}
\frac{\mathrm{d} \rho}{\mathrm{dt}}=-\rho \cdot \operatorname{div}_{\mathrm{y}} \mathrm{F}(\mathrm{t}, \mathrm{x}(\mathrm{t}), \mathrm{y}(\mathrm{t}), \mathrm{u}(\mathrm{t})), \\
\rho(0, y(0))=\rho_{0}\left(\mathrm{y}_{0}\right), \quad \mathrm{y}_{0} \in \mathrm{M}_{0},
\end{gathered}
$$

where $\rho_{0}\left(y_{0}\right)$ is density of particles distribution at the set $\mathrm{M}_{0}$.

We introduce following functionals:

$$
\begin{aligned}
& \mathrm{I}_{1}(\mathrm{u})=\mathrm{c}_{1} \int_{0}^{\mathrm{T}} \varphi_{1}(\mathrm{t}, \mathrm{x}(\mathrm{t}), \mathrm{u}(\mathrm{t})) \mathrm{dt}+\mathrm{c}_{2} \mathrm{~g}_{1}(\mathrm{x}(\mathrm{T})), \\
& \mathrm{I}_{2}(\mathrm{u})=\mathrm{c}_{3} \int_{0}^{\mathrm{T}} \Phi\left(\omega_{1}(\mathrm{t})\right) \mathrm{dt}+\mathrm{c}_{4} \cdot \mathrm{G}\left(\omega_{2}\right)
\end{aligned}
$$

Here $\mathbf{c}_{\mathrm{i}}(\mathrm{i}=1,2,3,4)$ are non-negative constant,

$$
\begin{aligned}
& \omega_{1}(t)=\int_{M_{t, u}} \varphi_{2}\left(t, x(t), y_{t}, \rho\left(t, y_{t}\right), u(t)\right) d y_{t}, \\
& \omega_{2}=\int_{M_{T, u}} g_{2}\left(y_{T}, \rho\left(T, y_{T}\right)\right) d y_{T},
\end{aligned}
$$

where set $\mathbf{M}_{\mathrm{t}, \mathrm{u}}$ is the cross-section of trajectories set of system (2) at the moment $t$, that can be obtained by time shift of the initial set $\mathrm{M}_{0}$ at corresponding control $\mathrm{u}=\mathrm{u}(\mathrm{t})$ :

$$
\begin{gathered}
M_{t, u}=\left\{\mathrm{y}_{\mathrm{t}} \mid \mathrm{y}_{\mathrm{t}}=\mathrm{y}\left(\mathrm{t}, \mathrm{y}_{0}, \mathrm{x}(\mathrm{t}), \mathrm{u}(\mathrm{t})\right)\right. \\
\left.\mathrm{y}_{0} \in \mathrm{M}_{0}, \mathrm{x}(0)=\mathrm{x}_{0}\right\},
\end{gathered}
$$

functions $\varphi_{1}, g_{1}, \varphi_{2}, g_{2}, \Phi, G$ are continuously differentiable functions, $\mathrm{T}$ is fixed. 
Together with the functional (6), which characterizes dynamics of program motion, and the functional (7), which characterizes beam of particles with taking into account their density of distribution, we introduce following functional:

$$
\mathrm{I}(\mathrm{u})=\mathrm{I}_{1}(\mathrm{u})+\mathrm{I}_{2}(\mathrm{u}) \text {. }
$$

The functional (11) estimates dynamics of program and perturbed motions and allows to conduct their optimization.

By using methods of investigation of functionals (6), (7) types presented at the work [1] variation of functional (11) (at admissible variation of control $\Delta \mathrm{u}(\mathrm{t})=\tilde{\mathrm{u}}(\mathrm{t})-\mathrm{u}(\mathrm{t}))$ can be represented in the following form:

$$
\begin{aligned}
& \delta I=-\int_{0}^{\mathrm{T}}\left(\chi^{*} \cdot \Delta_{\mathrm{u}} \mathrm{f}-\mathrm{c}_{1} \cdot \Delta_{\mathrm{u}} \varphi_{1}\right) \mathrm{dt} \\
& -\int_{0}^{\mathrm{T}} \int_{\mathrm{M}_{\mathrm{t}, \mathrm{u}}}\left(\mu^{*} \cdot \Delta_{\mathrm{u}} \mathrm{F}-\mathrm{c}_{3} \cdot \Phi^{\prime}\left(\omega_{1}\right) \cdot \Delta_{\mathrm{u}} \varphi_{2}\right) \mathrm{dy}_{\mathrm{t}} \mathrm{dt} \\
& -\int_{0}^{\mathrm{T}} \int_{\mathrm{M}_{\mathrm{t}, \mathrm{u}}}\left(v \cdot \Delta_{\mathrm{u}} \operatorname{div}_{\mathrm{y}} \mathrm{F}\right) \mathrm{dy_{ \textrm {t } }} \mathrm{dt} .
\end{aligned}
$$

Here $\Delta_{\mathrm{u}}$ denotes increment of a function at only increment of variable $\mathrm{u}$, for example, $\left.\Delta_{\mathrm{u}} \mathrm{f}=\mathrm{f}(\mathrm{t}, \mathrm{x}, \mathrm{u}+\Delta \mathrm{u})-\mathrm{f}(\mathrm{t}, \mathrm{x}, \mathrm{u})\right)$.

Auxiliary functions $\chi(\mathrm{t}), \mu\left(\mathrm{t}, \mathrm{y}_{\mathrm{t}}\right), \mathrm{v}\left(\mathrm{t}, \mathrm{y}_{\mathrm{t}}\right)$ satisfy the following systems along the trajectories of systems (1), (2), (4):

$$
\begin{aligned}
& \frac{\mathrm{d} \chi}{\mathrm{dt}}=-\left(\frac{\partial \mathrm{f}}{\partial \mathrm{x}}\right)^{*} \cdot \chi+\mathrm{c}_{1} \cdot\left(\frac{\partial \varphi_{1}}{\partial \mathrm{x}}\right)^{*} \\
& -\int_{\mathrm{M}_{\mathrm{t}, \mathrm{u}}}\left(\left(\frac{\partial \mathrm{F}}{\partial \mathrm{x}}\right)^{*} \cdot \mu+v \cdot\left(\frac{\partial \operatorname{div}_{\mathrm{y}} \mathrm{F}}{\partial \mathrm{x}}\right)^{*}\right) \mathrm{dy}_{\mathrm{t}} \\
& +c_{3} \cdot \Phi^{\prime}\left(\omega_{1}(t)\right) \cdot \int_{M_{t, u}}\left(\frac{\partial \varphi_{2}}{\partial x}\right)^{*} d y_{t} \\
& \frac{\mathrm{d} \mu}{\mathrm{dt}}=-\left(\frac{\partial \mathrm{F}}{\partial \mathrm{y}}+\mathrm{E} \cdot \operatorname{div}_{\mathrm{y}} \mathrm{F}\right)^{*} \cdot \mu \\
& -v \cdot\left(\frac{\partial \operatorname{div}_{\mathrm{y}} \mathrm{F}}{\partial \mathrm{y}}\right)^{*}+\mathrm{c}_{3} \cdot \Phi^{\prime}\left(\omega_{1}(\mathrm{t})\right) \cdot\left(\frac{\partial \varphi_{2}}{\partial \mathrm{y}}\right)^{*} \\
& \frac{d v}{d t}=-v \cdot \operatorname{div}_{y} F \\
& +c_{3} \cdot \Phi^{\prime}\left(\omega_{1}(\mathrm{t})\right) \cdot\left(\varphi_{2}-\rho \cdot \frac{\partial \varphi_{2}}{\partial \rho}\right),
\end{aligned}
$$

$$
\begin{aligned}
\chi(T)= & -c_{2} \cdot \frac{\partial g_{1}(x(T))^{*}}{\partial x} \\
\mu\left(T, y_{T}\right) & =-c_{4} \cdot G^{\prime}\left(\omega_{2}\right)\left(\frac{\partial g_{2}\left(y_{T}, \rho_{T}\right)}{\partial y}\right)^{*}, \\
v\left(T, y_{T}\right) & =-c_{4} \cdot G^{\prime}\left(\omega_{2}\right) \cdot\left(g_{2}\left(y_{T}, \rho_{T}\right)-\right. \\
& \left.-\rho_{T} \frac{\partial g_{2}\left(y_{T}, \rho_{T}\right)}{\partial \rho}\right),
\end{aligned}
$$

where $\rho_{\mathrm{T}}=\rho\left(\mathrm{T}, \mathrm{y}_{\mathrm{T}}\right), \mathrm{G}^{\prime}\left(\omega_{2}\right)=\mathrm{dG}\left(\omega_{2}\right) / \mathrm{d} \omega_{2}$, $\Phi^{\prime}\left(\omega_{1}\right)=\mathrm{d} \Phi\left(\omega_{1}\right) / \mathrm{d} \omega_{1}$.

The representation (12) of functional variation allows to construct various methods of optimization for functional (11).

\section{BEAM DYNAMICS MODELLING}

Let us consider charge particle dynamics in RFQ channel. Longitudinal motion in equivalent running wave can be represented in the following form:

$$
\frac{\mathrm{d} \beta}{\mathrm{dt}}=\frac{2 \mathrm{eU}_{\mathrm{L}} \Theta}{\mathrm{W}_{0} \mathrm{~L}} \cdot \cos \left(\widetilde{\omega} \cdot \tau-\Psi+\varphi_{\mathrm{s}}\right) .
$$

Here $\quad \beta=\dot{\mathrm{z}} / \mathrm{c}, \quad \tau=\mathrm{ct}, \quad \tilde{\omega}=2 \pi \omega / \mathrm{c}$, $\Psi=\int_{\mathrm{z}}^{\mathrm{z}_{\mathrm{s}}} \Omega(\xi) \mathrm{d} \xi=\Omega \Delta \mathrm{z}, \Omega=2 \pi / \mathrm{L}, \mathrm{U}_{\mathrm{L}}$ - intervane voltage, $\Theta$ - accelerating efficiency, $\mathrm{W}_{0}$ - rest mass energy, L - period length, $\omega$ - accelerating field frequency, $\varphi_{\mathrm{s}}$ - synchronous phase.

For synchronous particle $\tilde{\omega} \tau=\Omega z_{\text {s }}$ and, hence

$$
\begin{gathered}
\frac{\mathrm{d} \beta_{\mathrm{s}}}{\mathrm{d} \tau}=\frac{2 \mathrm{e} \mathrm{U}_{\mathrm{L}} \Theta}{\mathrm{W}_{0} \mathrm{~L}} \cos \varphi_{\mathrm{s}}, \\
\frac{d^{2}\left(z_{s}-z\right)}{d \tau^{2}}=\frac{2 e U_{L} \Theta}{W_{0} L}\left(\cos \varphi_{s}-\right. \\
\left.\quad-\cos \left(\Omega\left(z-z_{s}\right)+\varphi_{s}\right)\right),
\end{gathered}
$$

Let us make notations:

$$
\Omega_{0}{ }^{2}=\frac{4 \pi \mathrm{e}\left(\mathrm{U}_{\mathrm{L}} \Theta\right)_{\max }}{\mathrm{W}_{0} \mathrm{~L}_{0}{ }^{2}}, \eta=\frac{\left(\mathrm{U}_{\mathrm{L}} \Theta\right)}{\left(\mathrm{U}_{\mathrm{L}} \Theta\right)_{\max }},
$$

and use new variables:

$$
\psi=\Omega\left(\mathrm{z}_{\mathrm{s}}-\mathrm{z}\right), \tilde{\tau}=\Omega_{0} \tau .
$$

After all transformation equations (20), (21) takes form:

$$
\frac{\mathrm{d}}{\mathrm{d} \tilde{\tau}}\left(\mathrm{L} / \mathrm{L}_{0}\right)^{2}=2 \mathrm{k} \cdot \eta(\tilde{\tau}) \cdot \cos \varphi_{\mathrm{s}}(\tilde{\tau})
$$

and terminal conditions 


$$
\begin{aligned}
& \psi^{\prime \prime}+\frac{\left(L / L_{0}\right)^{2}}{\left(L / L_{0}\right)^{2}} \psi^{\prime}+\frac{\left(L / L_{0}\right)^{\prime \prime}}{\left(L / L_{0}\right)} \psi- \\
& -\frac{\eta(y)}{\left(L / L_{0}\right)^{2}}\left(\cos \varphi_{s}-\cos \left(\psi+\varphi_{s}\right)\right)=0
\end{aligned}
$$

where the stroke denotes the derivative with respect to $\tilde{\tau}$ and $\mathrm{k}=\Omega_{0} / \widetilde{\omega}$.

Various optimization problems of longitudinal motion can be formulated on the basis of equations (22), (23). Further we will consider the functions $\mathrm{u}_{1}=\eta(\tilde{\tau})$ and $\mathrm{u}_{2}=\varphi_{\mathrm{s}}(\tilde{\tau})$ as control functions.

It should be noted that all accelerators with the same plots $\varphi_{\mathrm{s}}(\tilde{\tau})$ and $\eta(\tilde{\tau})$ and with $\mathrm{k}=$ const has similar beam behaviour. The relation between unites $\tilde{\tau}$ and period number $\mathrm{N}$ is defined by $\mathrm{kN}=\tilde{\tau}$.

\section{OPTIMIZATION CRITERIA}

As the aim of RFQ structure optimization we consider the following: obtaining of maximal capture of particles under the acceleration regime; obtaining of required or maximal possible output energy; minimization of defocusing factor effect; obtaining of monotonicity of particles' grouping which reduces Coulomb forces' effect on the dynamics of charged particles, subsequently improves the dynamic process in RFQ channel.

Let $\mathrm{x}=\left(\mathrm{L} / \mathrm{L}_{0}\right)^{2}, \quad \mathrm{y}=\left(\mathrm{y}_{1}, \mathrm{y}_{2}\right)^{*}=\left(\psi, \psi^{\prime}\right)^{*}$, $\mathrm{M}_{0}=\left\{\mathrm{y} \mid-\pi \leq \mathrm{y}_{1} \leq \pi, \theta_{1} \leq \mathrm{y}_{2} \leq \theta_{2}\right\}$

For the process dynamics assessment we introduce functionals:

$$
\begin{gathered}
\mathrm{I}_{1}(\mathrm{u})=\mathrm{c}_{1} \int_{0}^{\mathrm{T}} \varphi_{1}\left(\mathrm{~A}_{\mathrm{def}}\right) \mathrm{d} \tilde{\tau}+\mathrm{c}_{2}(\mathrm{x}(\mathrm{T})-\overline{\mathrm{x}})^{2} \\
\mathrm{~A}_{\mathrm{def}}=\frac{2 \mathrm{k}^{2} \eta\left|\sin \varphi_{\mathrm{s}}\right|}{\left(\mathrm{L} / \mathrm{L}_{0}\right)^{2}}=\frac{2 \mathrm{k}^{2} \mathrm{u}_{1}\left|\sin \mathrm{u}_{2}\right|}{\mathrm{x}} \\
\mathrm{I}_{2}(\mathrm{u})=\mathrm{c}_{3} \int_{0}^{\mathrm{T}} \Phi\left(\mathrm{w}_{1}(\mathrm{t})\right) \mathrm{d} \tilde{\tau} \\
w_{1}(t)=\frac{d}{d \tilde{\tau}} \int_{M_{\tilde{\tau}, u}}\left(\psi^{2} \cdot \rho\right) d y_{\tilde{\tau}}= \\
\int_{M_{\tilde{\tau}, u}} 2 \psi \psi^{\prime} \rho\left(\tilde{\tau}, \psi, \psi^{\prime}\right) d y_{\tilde{\tau}}=\int_{M_{\tilde{\tau}, u}} 2 y_{1} y_{2} \rho d y_{\tilde{\tau}},
\end{gathered}
$$

Here $\varphi_{1}$ and $\Phi$ are penal functions, which can be introduced in following way:

$$
\varphi_{1}\left(\mathrm{~A}_{\mathrm{def}}\right)=\left\{\begin{array}{cc}
0, & \mathrm{~A}_{\mathrm{def}} \leq \overline{\mathrm{A}} \\
\left(\mathrm{A}_{\mathrm{def}}-\overline{\mathrm{A}}\right)^{2 \mathrm{p}}, & \mathrm{A}_{\mathrm{def}}>\overline{\mathrm{A}}
\end{array},\right.
$$

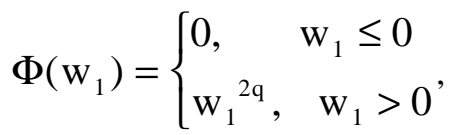

where $\mathrm{p}, \mathrm{q}$ are certain positive integer constants.

$A_{\text {def }}$ is defocusing factor; $\bar{x}=\left(\overline{\mathrm{L}} / \mathrm{L}_{0}\right)^{2}=\left(\bar{\beta} / \beta_{0}\right)^{2}$ is fixed value, which determines velocity of synchronous particle at the output of accelerator; $\rho=\rho\left(\tilde{\tau}, \psi, \psi^{\prime}\right)$ is density of particle distribution.

Functional (24) integrally estimates the deviation of defocusing factor from given value and accounts the deviation of synchronous particle velocity from given one at the output of accelerator. Functional (25) characterizes velocity of variation of mean square phase distribution. In this connection, condition $\mathrm{w}_{1} \leq 0$ ensures the monotonicity of grouping and simultaneously ensures the capture of particles into acceleration mode.

On the basis of variation (12) for the functional (26) numerical methods of optimization which allow joint minimization of functionals (24), (25). The realization of these methods shows their effectiveness.

\section{CONCLUSION}

Under RFQ structure optimization following parameters are considering as controlling: voltage between electrodes, modulation of electrodes, mean value aperture on the period of modulation, synchronous phase, i.e. each cell of developing structure is described by all parameters for each cell ([2]). In this case full-scale modeling of particles dynamics and conducting of optimization require much time and numerous attempts. Such approach seems to be reasonable for improvement of parameters in the vicinity of chosen already variant.

Thus for the practical use of optimization methods it is necessary to use step by step method of choice of RFQ structure parameters. At each stage of this calculation various mathematical models with growing level of complexity should be considered.

In this paper the simple mathematical model which describes beam dynamics in RFQ channel is suggested, that can be used on the initial stage of optimization. Suggested mathematical models of optimization and developed methods and approaches of their analysis allow effective optimization of the RFQ channel.

It should be noted, that developed methods of optimization can be applied to the optimization problem of intense beam dynamics.

\section{REFERENCES}

[1] Ovsyannikov D.A., "Modeling and Optimization of Charged Particle Beam Dynamics", Leningrad State University, Leningrag, 312p., (1990).

[2] Drivotin O.I. , Loukianova A.E., Ovsyannikov D.A., Garvish Yu.N., Svistunov Yu.A. , Vorogushin M.F., " The Choice of Acceleration Structure for PET-System", EPAC'96, Proceedings, Barselona, Spain, Vol.1, p.783-785, (1996). 